

Wild honeybees live in hollowed out trees.

APIOLOGY

\section{Darwinian bee-keeping: lessons from the wild}

\section{A timely treatise on the plight of the honeybee Apis mellifera grips Gene E. Robinson.}

$\mathrm{F}$ or the past 15 years, honeybee-colony deaths have become alarming. The European honeybee, Apis mellifera, accounts for nearly half of all crop pollination worldwide, and the annual losses - as high as $40 \%$ in North America - are unsustainable. It's a cruel twist of fate that this central player in food security has never been as visible as now, when it is in serious trouble.

Much has been written about the honeybee crisis, its causes and its consequences. We now understand that the primary culprits are the 'four Ps': pesticides, parasites, pathogens and poor nutrition, which all interact. But Thomas Seeley's The Lives of Bees sounds a fresh note, providing a new perspective on the roots of the crisis and a provocative proposal for how to deal with it. Unusually, its focus is honeybees in the wild.

Seeley is a world expert on honeybee behaviour. His previous books, such as Wisdom of the Hive (1995) and 2010's Honeybee Democracy, elevated this social insect

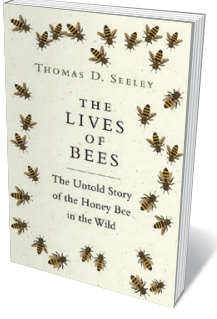

The Lives of Bees: The Untold Story of the Honey Bee in the Wild THOMAS D. SEELEY Princeton University Press (2019) tially wild animals that can live very well on their own. Because they seemed to take nicely to the variety of beehives humans have invented over the 10,000-year history of beekeeping, no one thought to reveal the truly secret life of bees. And very few biologists beyond Seeley have the vision and tenacity to conceive of and perform a long-term study of the type that underpins this book.

That 40-year systematic project aims to illuminate the honeybee's natural life. Most of the studies were done by Seeley and a group of talented students at Cornell University in Ithaca, New York, whose work is fully and frequently acknowledged. Some involve observations of wild colonies living in 'bee trees', with cavities large enough for a swarm to create a nest. Others are experiments simulating the conditions in a bee tree, using manufactured hives. Elegantly simple in design, the research is expertly synthesized by Seeley to give us a vivid glimpse of how honeybees live when left to their own devices: how their colonies develop; how they build, organize, defend, and heat and cool their nests; and how they collect and store food. It is the most complete picture yet of the honeybee's natural history.

Seeley contrasts this with life in a manufactured hive. For example, honeybees stay warm by shivering with their powerful thoracic flight muscles. This is one of many fascinating behaviours reliant on the coordinated activities of tens of thousands of individual bees to produce an outcome that matters to the whole colony. But this mechanism is much more effective in a bee tree, which tends to have thick walls, than in standard thin-walled beehives.

Seeley and his colleagues learnt this by placing temperature sensors in hives designed to simulate nest cavities in trees, identical except for wall thickness, and located side by side. Temperature fluctuations are much greater in hives, and the bees have to work harder to maintain the temperature of their brood - which can add stress to the life of a colony.

\section{HIVE OF INDUSTRY}

To pull off his complex project, Seeley had to contend with black bears destroying his colonies, vicissitudes of weather necessitating the gathering of more data, and the catastrophic invasion of the parasitic mite Varroa destructor. The mite, which feeds on honeybee fat tissue and transmits pathogens such as deformed wing virus, has devastated honeybee populations in many parts of the world. This unremitting loss of colonies changed the focus of Seeley's book. He discovered how conditions in the wild make it possible for them to withstand $V$. destructor.

Seeley proposes that bee-keepers use knowledge about wild populations to change how they practise their craft. He calls for "Darwinian beekeeping", modelled after Darwinian medicine, which posits that mismatches between the current environment and the environment to which an organism originally adapted diminish the organism's fitness. For Seeley, this relates mainly to the differences between life in a bee tree and life in a beehive, especially in 
the northeastern United States. He spends less time on environmental changes at larger spatial scales, such as land-use patterns and climate change. His practical suggestions amount to a "kinder and gentler" approach that takes advantage of bees' natural tendency to adapt to their local environment, and minimizes disruption to the natural architecture of their nests.

Darwinian bee-keeping is spurred by how modern apiculture has drastically changed bees' lives. But 'modern' movable-frame hives and smokers (used to calm bees) were invented in the mid-nineteenth century, along with the "The coordinated honey extractor. I activities of tens see little technical of thousands of individual bees produce an outcome that matters to the whole colony." innovation since then. Bee-keepers barely use processes that have become staples in other sectors of agriculture, such as intense genomic-based breeding or manipulation of physiology and behaviour by hormones and pheromones. Even migratory bee-keeping (moving hives to orchards and fields when flowers are blooming), which dominates the industry today, was invented in Egypt about 5,000 years ago.

How practical is Seeley's strategy for enlightened bee-keeping? Two traits exhibited by bees in the wild - small colony sizes and frequent colony reproduction through swarming - are linked to greater resilience to parasites and pathogens. But these traits also diminish the colonies' effectiveness as pollinators and honey producers. From the human perspective, smaller colonies are less productive ones.

Although passionate in his advocacy of Darwinian bee-keeping, Seeley gives us both sides of the story. Implicitly, he asks us to contemplate the current human hegemony. How do we care for bees so they can provide for us? By framing honeybee natural history in this way, Seeley has written a highly technical but eloquent book on the bee that will also appeal to those interested in sustainable agriculture.

Bee-keeping is at a crossroads. In the era of CRISPR gene editing, should we save the bees with new technology, or with new insights gleaned from their 30-million-year evolutionary history? I hope we can pioneer a third way, and do both. As the biblical Proverbs 6:6 notes of the ant, we need to go to the bee, "consider its ways and be wise". Seeley has done that better than anyone.

Gene Robinson is a honeybee biologist in the Department of Entomology, and director of the Carl R. Woese Institute for Genomic Biology at the University of Illinois at Urbana-Champaign.

e-mail:generobi@illinois.edu

\section{Books in brief}

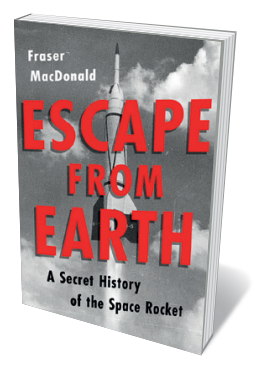

\section{Escape from Earth}

Fraser MacDonald PuBLICAFFAIRS (2019)

In the 1930s, many scientists derided rocketry. That failed to deter aeronautical engineer Frank Malina from developing the first US rocket to achieve extreme altitude: the WAC Corporal. Fraser MacDonald's taut, deeply researched account of Malina's career is packed with luminaries such as Theodore von Kármán, and insights into the zeitgeist of a fraught era. Equally fascinating is Malina, who co-founded the Jet Propulsion Laboratory in Pasadena, California, yet - becoming "stuck in the reputational mire of McCarthyism" was written out of space-age history because of his communist past.

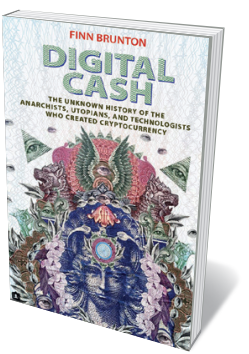

Digital Cash

Finn Brunton PRINCETON UNIVERSITY PRESS (2019)

Cryptocurrencies seem to have sprung up from nowhere. But as communications expert Finn Brunton reveals in this knotty, engrossing technological history, their roots stretch back decades. Brunton examines paper money as manufactured object and abstract quantity, then digs into the annals of experimental cash minted by a succession of radicals, 'cypherpunks' and digital utopians. It's quite a ride, from cryptographer David Chaum's failed DigiCash initiative of 1989 through to the bitcoin saga - by way of "a wall of lava lamps, and a tank of frozen human heads".

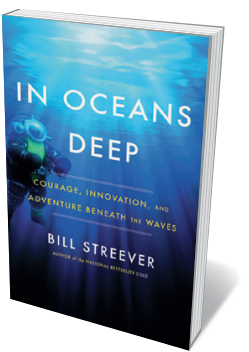

In Oceans Deep

Bill Streever LITTLE, BROWN (2019)

In this homage-cum-history of human endeavour in the ocean depths, biologist, writer and diver Bill Streever brings to light a region less explored than the Moon. He meets Don Walsh, who with Jacques Piccard made the first descent to the oceans' deepest point, some 11 kilometres down, in 1960. And he delineates the physics and physiology of free and 'saturation' diving, submersibles such as Cornelis Drebbel's seventeenth-century wood-and-leather vessel, and the robots slated to replace deep-ocean researchers. Streever ends movingly, with a pledge to conserve Earth's abyssal riches.

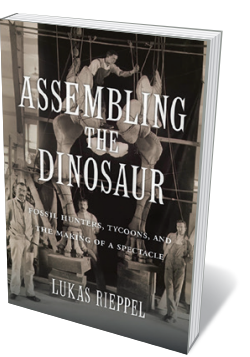

\section{Assembling the Dinosaur}

Lukas Rieppel HARVARD UNIVERSITY PRESS (2019)

Corporate buccaneering and political corruption marred the US 'Gilded Age' of the late nineteenth century; meanwhile, fossil finds such as Triceratops made the nation a global centre for vertebrate palaeontology. Science historian Lukas Rieppel traces the commingling of capitalism and science in this nuanced study. Thrilling museum fossil displays burnished the reputations of philanthropists who backed the institutions, such as Andrew Carnegie and J. P. Morgan - even as the tycoons twisted the dinosaurs' demise into a metaphor for the advance of 'enlightened' corporate culture.

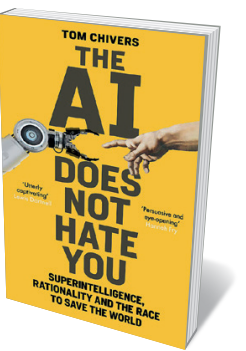

\section{The Al Does Not Hate You}

Tom Chivers WEIDENFELD \& NICOLSON (2019)

The existential threat of artificial intelligence (Al) has been much chewed over, but science writer Tom Chivers explores a fresh angle. In his witty, wide-ranging book, we meet a global community of Al analysts: the entrepreneurs, economists and philosophers inspired by Al theorist Eliezer Yudkowsky and known as the Rationalists. Their original insights into the near-future ethical and societal complexities of this techno-revolution convince us that they have, as Chivers puts it, "taken the niche, practically dystopian-science-fiction idea of Al risk and made people take it seriously". Barbara Kiser 